\title{
FECUNDIDADE DE Chrysoperla raimundoi FREITAS \& PENNY, 2001 (NEUROPTERA: CHRYSOPIDAE) ORIUNDAS DE LARVAS CRIADAS EM AMBIENTES COM DIFERENTES TEMPERATURAS.
}

\author{
Taís Carmona Lavagnini1 ${ }^{1,2}$, Sérgio de Freitas ${ }^{1,3}$
}

\begin{abstract}
'Departamento de Fitossanidade, Faculdade de Ciências Agrárias e Veterinárias, UNESP, Via de acesso Prof Paulo Donato Castellane, s/n, 14884-900, Jaboticabal - SP, Brasil.

${ }^{2}$ taisc_lavagnini@yahoo.com.br

${ }^{3}$ serfre@fcav.unesp.br
\end{abstract}

\section{RESUMO}

O sucesso dos crisopídeos em programas de controle biológico de pragas agrícolas está intimamente relacionado com sua capacidade reprodutiva. Portanto, o objetivo deste trabalho foi verificar a influência de diferentes temperaturas e as diferenças entre gerações quanto a capacidade reprodutiva de Chrysoperla raimundoi. As fases jovens foram criadas em quatro ambientes, três com temperaturas constantes $\left(19^{\circ} \mathrm{C}, 25^{\circ} \mathrm{C}\right.$ e $\left.31^{\circ} \mathrm{C}\right)$ e um com flutuação da temperatura. Foram observados a duração do período de pré-oviposição, o número total de ovos, a média diária de ovos por fêmea e a fertilidade desses ovos. De acordo com os resultados obtidos, não houve diferença significativa para quaisquer dos parâmetros analisados mostrando que nem diferentes temperaturas, nem imaturos de diferentes gerações podem alterar a capacidade reprodutiva de C. raimundoi.

Palavras-chave: capacidade reprodutiva, controle biológico, crisopídeos, predador

\section{FECUNDITY OF Chrysoperla raimundoi FREITAS \& PENNY, 2001 (NEUROPTERA: CHRYSOPIDAE) FROM LARVAE REARED UNDER DIFFERENT TEMPERATURES}

\begin{abstract}
The success of green lacewings in biological control programs for agricultural pests is related to their reproductive capacity. Therefore, the purpose of this study was to observe the influence of different temperatures and differences among generations in the reproductive capacity of Chrysoperla raimundoi. The immature stages were reared in four conditions: three with constant temperatures $\left(19^{\circ} \mathrm{C}, 25^{\circ} \mathrm{C}\right.$ e $\left.31^{\circ} \mathrm{C}\right)$ and the fourth one with fluctuation of temperature. The following parameters were evaluated: duration of the preoviposition period, total number of eggs, number of eggs per day per female and the fertility of these eggs. The results indicated that different temperatures and larvae from different generations do not influence the reproductive capacity of C. raimundoi.
\end{abstract}

Key words: biological control, green lacewings, predator, reproductive capacity

\section{INTRODUÇÃO}

Os crisopídeos são liberados no campo na forma de ovos embrionados ou larvas, e o seu sucesso pode estar relacionado com a capacidade de sobrevivência e com a reprodução desses insetos nos agroecossistemas (Angelini, 2004). 
Os limites da faixa favorável de temperatura para oviposição são geralmente os da mesma ordem para o desenvolvimento de estágios imaturos, mas não precisam ser necessariamente similares. Outros fatores além da temperatura, como umidade relativa do ar, alimento e o número de outros indivíduos presentes no ambiente, podem influenciar a oviposição; o número de ovos por dia também pode ser influenciado pela idade do inseto (Andrewartha, 1954).

Estudos realizados com fêmeas adultas de Chrysoperla externa mantidas a $21,1^{\circ} \mathrm{C}$ mostraram que o período de pré-oviposição durou, em média, 10 dias e que, em média, elas ovipositaram 284 ovos em um período de 30 dias (Albuquerque et al, 1994). Observou-se que adultos de Chrysoperla raimundoi mantidos a $25^{\circ} \mathrm{C}$ apresentaram duração do período de pré-oviposição de 3,6 dias, oviposição diária de 7,3 ovos/dia/fêmea e oviposição total de 451,4 ovos/ fềmea; a viabilidade dos ovos foi estimada em $85,9 \%$ (Pessoa et al, 2004).

Devido a recente descrição da espécie poucos estudos têm sido realizados com Chrysoperla raimundoi no que tange a sua biologia. Portanto, o objetivo deste estudo foi verificar se a temperatura do ambiente de criação das larvas de Chrysoperla raimundoi interfere na fecundidade, como também se larvas de diferentes gerações apresentam diferenças.

\section{MATERIAL E MÉTODOS}

As fases jovens da geração $F_{2}$ foram criadas em três ambientes sendo que dois deles tinham temperaturas constantes de $25^{\circ} \mathrm{C}$ e $31^{\circ} \mathrm{C}$, com umidade relativa de $70 \pm$ $10 \%$ e fotoperíodo de 12 horas. Já no terceiro ambiente houve flutuação dos fatores abióticos como temperatura, fotoperíodo e umidade relativa, pois o experimento foi mantido em uma área coberta nas dependências externas do laboratório. Este último tratamento foi realizado durante os meses de janeiro e fevereiro e, portanto os fatores abióticos flutuaram de acordo com as características da estação do verão.

Ao final do período pupal os adultos obtidos foram separados em gaiolas de tubo de PVC $(20 \times 10 \quad \mathrm{~cm})$ revestidas internamente com 1 folha de papel sulfite, somente um casal por gaiola, sendo posteriormente colocados em sala climatizada a $25^{\circ} \mathrm{C}$, para avaliação da capacidade reprodutiva. Os indivíduos nas gaiolas foram alimentados com dieta à base de mel e lêvedo de cerveja na proporção 1:1. Diariamente os ovos foram retirados das gaiolas e semanalmente observada a fertilidade dos mesmos. Eles eram individualizados em placas de teste ELISA coberta com filme plástico e depois de dois dias era observada a porcentagem de ovos férteis. Os adultos foram sacrificados com 40 dias de idade.

Para análise da influência de baixas temperaturas sobre a capacidade reprodutiva, as fases jovens foram criadas em dois ambientes com temperaturas constantes de $19^{\circ} \mathrm{C}$ e $25^{\circ} \mathrm{C}$, com fotoperíodo de 12 horas e umidade relativa de $70 \pm 10 \%$. Utilizou-se a geração $\mathrm{F}_{4}$. A avaliação da capacidade reprodutiva seguiu a mesma metodologia utilizada para os adultos da geração $F_{2}$.

Para verificação das diferenças entre as gerações utilizou-se os dados obtidos dos adultos das gerações $\mathrm{F}_{2}$ e $\mathrm{F}_{4}$, cujas fases jovens foram criadas à $25^{\circ} \mathrm{C}$. Foram observados a duração do período de préoviposição, o número total de ovos por fêmea, a média diária de ovos por fêmea e a fertilidade desses ovos.

\section{RESULTADOS E DISCUSSÃO}

Fecundidade dos adultos da geração $F_{2}$, cujas fases jovens foram criadas em diferentes temperaturas.

O período de pré-oviposição (Tabela 1), para os adultos cujas fases imaturas foram 
Tabela 2. Duração em dias do período de pré-oviposição, número total de ovos por fềmea, média diária de ovos por fêmea e fertilidade (\%) de ovos de Chrysoperla raimundoi cujos ovos e larvas foram submetidos à temperatura $25^{\circ} \mathrm{C}$ e $19^{\circ} \mathrm{C}$ na geração $\mathrm{F}_{4}$.

\begin{tabular}{ccc} 
& $\mathbf{2 5}^{\mathbf{}} \mathbf{C}$ & $\mathbf{1 9}^{\circ} \mathbf{C}$ \\
\hline Período de pré oviposição & $8,5 \mathrm{a}$ & $6,5 \mathrm{a}$ \\
Total de ovos/fềmea & $257,7 \mathrm{a}$ & $305,9 \mathrm{a}$ \\
Ovos/dia/fêmea & $9,3 \mathrm{a}$ & $9,2 \mathrm{a}$ \\
Fertilidade & $87,6 \mathrm{a}$ & $93,3 \mathrm{a}$ \\
\hline dias seguidas de mesma letra na linha não são significativamente diferentes pelo teste Tukey a $5 \%$ de
\end{tabular}

Influência de diferentes gerações sobre a capacidade reprodutiva.

Os adultos obtidos da geração $F_{2}$ e $F_{4}$ não apresentaram diferença significativa na duração do período de pré-oviposição (Tabela 3).

Tabela 3. Duração em dias do período de pré-oviposição, número total de ovos por fêmea, média diária de ovos por fêmea e fertilidade (\%) de ovos de Chrysoperla raimundoi cujos ovos e larvas foram submetidos à temperatura $25^{\circ} \mathrm{C}$ nas gerações $\mathrm{F}_{2}$ e $\mathrm{F}_{4}$.

\begin{tabular}{ccc} 
& $\mathbf{2 5}^{\circ} \mathbf{C} \mathbf{F}_{\mathbf{2}}$ & $\mathbf{2 5}^{\mathbf{0}} \mathbf{C} \mathbf{F}_{\mathbf{4}}$ \\
\hline Período de pré-oviposição & $9,4 \mathrm{a}$ & $8,5 \mathrm{a}$ \\
Total de ovos/fêmea & $405,9 \mathrm{a}$ & $257,7 \mathrm{a}$ \\
Ovos/dia/fêmea & $13,4 \mathrm{a}$ & $9,3 \mathrm{a}$ \\
Fertilidade & $86,2 \mathrm{a}$ & $87,6 \mathrm{a}$ \\
\hline
\end{tabular}

*Médias seguidas de mesma letra na linha não são significativamente diferentes pelo teste Tukey a $5 \%$ de probabilidade.

Foi observada redução no número total de ovos por fêmea entre as gerações $\mathrm{F}_{2} \mathrm{e} \mathrm{F}_{4}$, contudo esta diferença não foi significativa. Entre a média diária de ovos por fêmea e a porcentagem de ovos férteis também não houve diferença significativa (Tabela 3 ).

Os resultados obtidos quanto à capacidade reprodutiva são positivos, pois indicam que não é necessário estabelecer linhagens em insetários uma vez que os dados observados são viáveis até a geração $\mathrm{F}_{4}$, tanto quanto os observados para a geração $F_{2}$. Pode-se afirmar também que os acasalamentos consangüíneos entre os indivíduos podem gerar endogamia e diminuição na variabilidade genética, entretanto esta possivel redução na variabilidade genética não afetou negativamente os parâmetros analisados, pois eles não diferiram significativamente entre si para as gerações $\mathrm{F}_{2}$ e $\mathrm{F}_{4}$.

\section{AGRADECIMENTO}

À Prof ${ }^{\mathrm{a}}$. Dr ${ }^{\mathrm{a}}$. Adriana Coletto Morales pela revisão e sugestões.

\section{REFERÊNCIAS BIBLIOGRÁFICAS}

ALBUQUERQUE, G. S.; TAUBER, C. A.; TAUBER, M. J. 1994. Chrysoperla externa (Neuroptera: Chrysopidae): life history and potencial for biological control in Central and South America. Biological Control, Netherlands, 4, p. 8-13.

ANDREWARTHA, H. G.; BIRCH, L. C. 1954. Weather: Temperature, p.129171. In: Andrewartha, H. G.; Birch, L. C. (ed.). The Distribution and Abundance of Animals, London, The University of Chicago Press, 782 p. 
ANGELINI, M. R.; FREITAS, S. 2004. Desenvolvimento pós-embrionário e potencial reprodutivo de Chrysoperla externa (Hagen) (Neuroptera: Chrysopidae), alimentada com diferentes quantidades de ovos de Sitotroga cerealella (Lepidoptera: Gelechiidae). Acta Scientiarum. Agronomy, Maringá, 26:4, p. 395-399.
PESSOA, L.G.A.; FREITAS, S.; GARDIM, S.; RODRIGUES, K. C. 2004. Potencial reprodutivo de adultos de Chrysoperla raimundoi Freitas \& Penny (Neuroptera: Chrysopidae) em função da alimentação larval. Arquivos do Instituto Biológico, São Paulo, 71:4, p. 519-521. 